\title{
Non-numerical Distance and Size Effects in an Ant
}

\author{
Marie-Claire Cammaerts (Corresponding Author) \\ Independent researcher, retired from the Biology of Organisms Department, University of \\ Brussels, Belgium. E-mail: mccammaerts@gmail.com
}

\begin{abstract}
Roger Cammaerts
Independent researcher, retired from the Natural and Agricultural Environmental Studies

Department (DEMNA) of the Walloon Region, Belgium
\end{abstract}

Received: Feb. 3, 2020 Accepted: Apr. 12, 2020

doi:10.5296/jbls.v11i2.16895 URL: https://doi.org/10.5296/jbls.v11i2.16895

\begin{abstract}
The distance effect (the fact that the individuals' discrimination between two similar elements increases with the magnitude of the distance between them) as well as the size effect (the fact that the individuals' discrimination between two similar elements decreases with the size of these elements) have been largely reported in vertebrates but not in invertebrates. Here, we demonstrate their existence in an ant, using operant conditioning to visual cues (black circles) of different dimensions. The two effects were obvious and differed from one another. Both effects could be accounted for Weber's law, but it was here not tempted to verify if they are in line with this law by defining the just noticeable difference the ants can perceive between the cues.
\end{abstract}

Keywords: conditioning, Myrmica sabuleti, visual perception, Weber's law

\section{Introduction}

The sensory perception of a difference between two intensities of a stimulus depends on the amplitude of their difference (i.e. the distance effect) and on the magnitude of the two stimuli (i.e. the size effect). The distance effect accounts for the fact that two close intensities are more difficult to distinguish than two intensities largely differing. The size effect reflects the fact that the sensory perceptions of two stimuli which differ in intensity by a given amount are harder to discriminate when the magnitude of these stimuli is large.

Such magnitude effects applied to human psychophysical sensory functions are known since a long time (e.g. Cattell, 1902: size effect using light intensities; Kellogg, 1931: distance effect using brightness; Stevens, 1961: distance effect using diverse stimuli; Curtis et al., 
1973: distance effect using circle surfaces; Moyer \& Bayer, 1976: distance effect using circles or symbols (labels) corresponding to circles that are their referents; Cavonius \& Mollon, 1984: distance effect using colors). In non-human vertebrates, distance effect between various forms was shown in capuchin monkeys (Cebus apella) by D'Amato \& Colombo (1990).

Distance and size effects also apply to the comparison of symbolic (written) numbers and non-symbolic amounts (numerosities). In humans, these effects were first demonstrated by Moyer \& Landauer (1967) by using single digit comparison tasks. Buckley \& Gillman (1974) showed that distance effect was similar for single digit and dot pattern comparisons. Size effect using dot patterns was shown by Van Oeffelen \& Vos (1982).

In animals, distance effect for numerosity was first shown in pigeons (Rilling \& McDiarmid, 1965). In rhesus monkeys (Macaca mulatta), distance effect using numerical symbols (arabic numerals) corresponding to quantities of food pellets was shown by Washburn \& Rumbaugh (1991). In rhesus monkeys also, distance and size effects were shown by using numerosity ordering (Brannon \& Terrace, 2000) and numerosity bisection (Jordan \& Brannon, 2006). Numerosity size effect was also shown in crows (Corvus corone) by Ditz \& Nieder (2016) and in an ant, Myrmica sabuleti, by Cammaerts \& Cammaerts (2020).

The distance and size effects are attributed to the representation of intensities (i.e. concrete quantities as well as symbols such as digits representing quantities) on a mental number line (Cohen Kadosh et al., 2008).

The distance effect accounts for the fact that quantities (physical parameters or numbers) are positioned on a mental number line according to their magnitude and that a comparison between them is easier when their numerical distance is larger (Dehaene, 1992). The size effect accounts for the fact that larger quantities (or numbers) are represented on the mental number line more vaguely than are smaller ones (Dehaene et al., 1998).

The size effect and, to a lower extend, the distance effect are expressions of a physiological trait called the Weber's law which states that the lowest change of a stimulus which can be perceived (dS) is proportional to the magnitude of this stimulus (S). Another formulation is that this just noticeable difference is a constant ratio of the stimulus magnitude $(\mathrm{dS}=\mathrm{KS})$. This has been experimentally shown in humans using different kinds of stimuli including non-numerical ones such as, among others, tactile stimulation (Francisco et al., 2008). However, for some stimuli such as pure-tone acoustic intensities, Weber's law is not strictly verified (McGill, \& Goldberg, 1968) as it depends, among others, on the wavelength of the sound (Carlyon, \& Moore, 1984).

Both distance and size effects also reflect the fact that performance comparison between numbers (reflecting quantities) depends on their ratio (Krajcsi \& Koujouharova, 2017). As for animals, rhesus monkeys were found to represent numerosity ratios as predicted by Weber's law (Jordan \& Brannon, 2006). Numerosity discrimination in pigeons also follows Weber's law (Emmerton \& Renner, 2006). However, distance effect, size effect and Weber's law still need to be examined in invertebrates. 


\section{MlMacrothink}

The neuronal coding of these effects can be explained by a continuous and noisy representation of numbers (reflecting quantities) on the mental number line, the mental representation of numbers overlapping as their magnitude increases. This is called the Analog Number System (ANS, Brannon \& Merritt, 2011), a notion already implicitly reported by Dehaene (1992). Although the distance and size effects are observable in both non-symbolic (e.g. by using dots) and symbolic number processing (Krajcsi et al., 2016), only non-symbolic comparison is supported by the ANS model (Krajcsi et al., 2018), what is also suggested by the use of a digit-color synesthete (Cohen Kadosk et al., 2008). The ANS works according to Weber's law (Merten \& Nieder, 2008), what can be explained by postulating that a stimulus is mentally scaled onto a non-linear representation of its sensation, the scale being a logarithmic or a power function (Dehaene, 2003).

Here we intend to examine the existence of a distance and a size effect in workers of the ant M. sabuleti, not by using the ants' numerosity capabilities, but by using their response to visual cues, i.e. black circles, of different sizes. We investigated on the distance and the size effects, we only briefly looked if they could depend on Weber's law, and we intend to experimentally examine in a next paper if Weber's law can effectively be applied to ants.

\section{Material and Methods}

\subsection{Collection and Maintenance of Ants}

The experiments were conducted on twelve colonies, labeled A to F and A' to F', collected in June 2019 at Marchin (Condroz, Belgium) and in September 2019 at Olloy/Viroin (Ardenne, Belgium), each time in an abandoned quarry. These colonies contained 200 - 500 workers, a queen and brood. They were maintained in the laboratory in two to three glass tubes half filled with water, a cotton plug separating the ants from the water. The nest tubes of each colony were set in a tray $(34 \mathrm{~cm} \times 23 \mathrm{~cm} \times 4 \mathrm{~cm}$ or $30 \mathrm{~cm} \times 15 \mathrm{~cm} \times 5 \mathrm{~cm}$ ) which served as foraging area. In these trays, pieces of Tenebrio molitor larvae (Linnaeus, 1758) were deposited three times per week, and cotton plugged tubes filled of sugar water were permanently set. The ambient temperature was $c a 20^{\circ} \mathrm{C}$, the humidity $80 \%$, the lighting 330 lux while working on ants, and the electromagnetism $2 \mu \mathrm{Wm}^{2}$. These environmental conditions are optimum for the species.

\subsection{Experimental Design}

The ants were trained on their foraging area, with a stand bearing the black circle they were expected to memorize set near the food and another stand bearing the black circle they should not memorize set far from the food (Figure 1, left part; Figures 3, 4, left part). The ants were tested in a separated tray $(21 \mathrm{~cm} \times 15 \mathrm{~cm} \times 7 \mathrm{~cm})$ the border of which having been slightly covered with talc to prevent ants escaping, and in which two stands identical to those presented during training, but novel and never used, were placed at about seven centimeters from one another (Figure 1, right part; Figures 3, 4, right parts). 


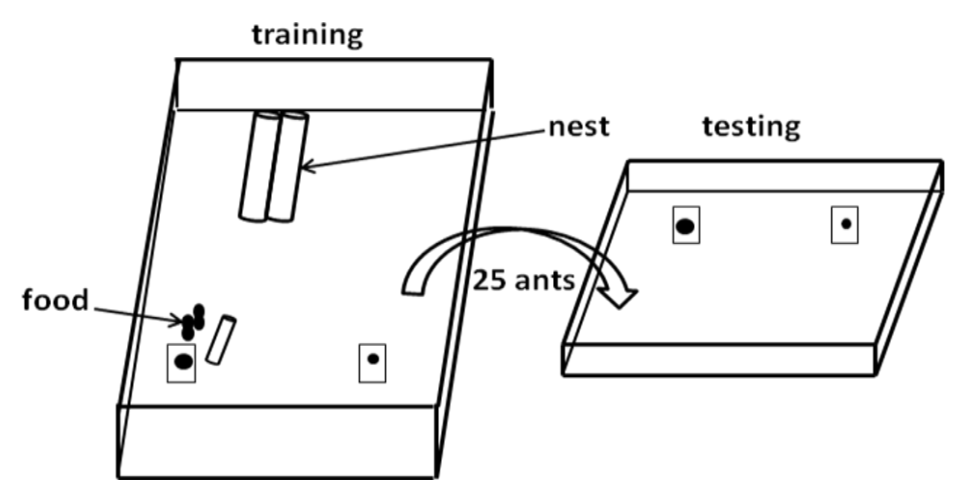

Figure 1. Experimental design

The ants were trained in their foraging area, the cue (tied to a stand) to memorize being set near the food and that to avoid being set far from food. They were tested, after 7, 24, 31, and 48 training hours, in a separate tray into which the two cues they saw during training were present. The ants approaching each of these two cues at a shorter distance than $2 \mathrm{~cm}$ were counted 20 times over 10 minutes, this allowing calculating the ants' conditioning score.

\subsection{Cues Presented to the Ants}

The cues presented to the ants were black circles of different dimensions, their diameter equaling 2, 4, 6, 8, 10, 12 or $14 \mathrm{~mm}$ according to the experiment performed (see below, Experimental Planning, and Figure 2, lower part). These circles were drawn in the middle of a $2 \mathrm{~cm} \times 2 \mathrm{~cm}$ paper square using a PC. They were then printed, cut, and tied each one on a stand (Figure 2, upper part; Figures 3, 4). Each stand was made of strong white paper (Steinbach $\left.{ }^{\circledR}\right)$; they had a vertical $(2 \mathrm{~cm} \mathrm{x} 2 \mathrm{~cm})$ and a horizontal part [2 x $\left.(1 \mathrm{~cm} \mathrm{x} 0.5 \mathrm{~cm})\right]$ which, duly folded, allowed the stand staying vertically.

\subsection{Ants'Training}

The ants were continuously trained during two days (= operant conditioning), and tested four times over these two days. For examining the distance effect, they were maintained in the large used trays and fed as explained in the subsection 'Collection and maintenance of ants'. For examining the size effect (which could be less easy to observe than the distance effect), the ants were maintained in the small used trays, they were deprived of food during one day before training, and during training some sugared milk was poured on the meat. Each training day, the ants present in the vicinity of the two presented cues were counted several times over 24 hours, and the mean of these counts was established (Tables 1, 4, last column). These counts did not require statistical analysis. 


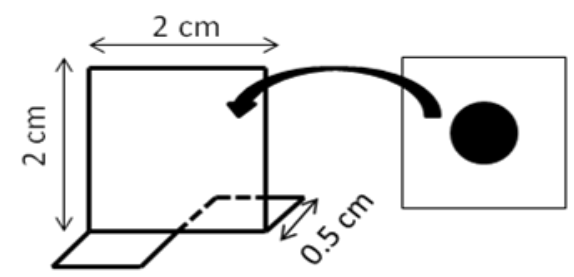

Distance effect:

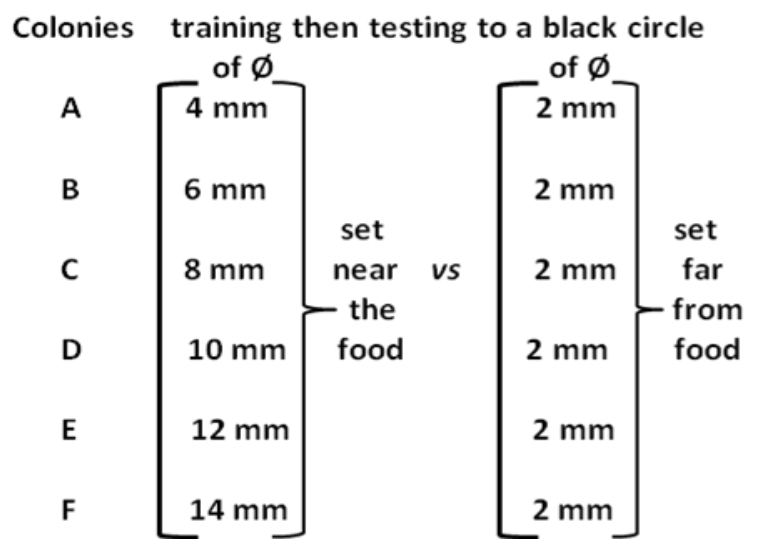

Size effect :

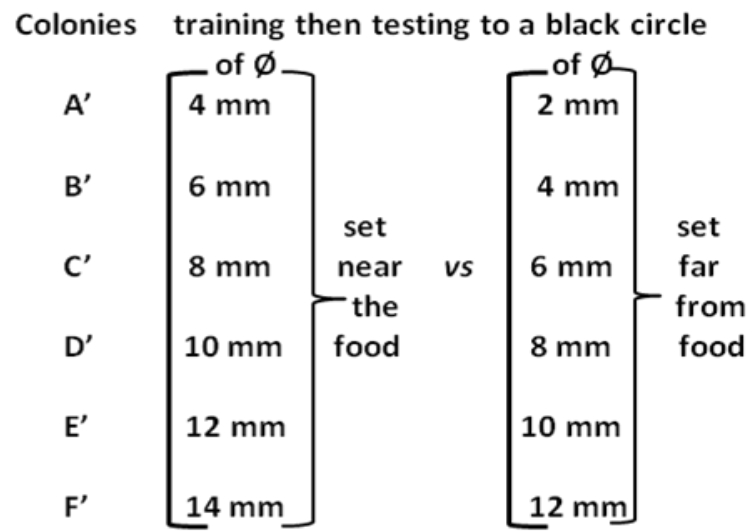

Figure 2. Cues presented to the ants

The cues were circles of a different diameter, each one being tied to a stand (upper schema). The distance effect was studied by presenting to the ants, near their food, a circle the diameter of which equaled 4 to $14 \mathrm{~mm}$, and far from the food, a circle the diameter of which equaled 2 $\mathrm{mm}$. The size effect was studied by presenting to the ants, near their food, a circle the diameter of which varied from 4 to $14 \mathrm{~mm}$, and far from food, a circle the diameter of which varied from 2 to $12 \mathrm{~mm}$ respectively.

\subsection{Ants’Testing}

For each experiment, the ants were tested after 7, 24, 31, and 48 training hours. For this purpose, 25 ants of a colony were transported into the tray devoted to testing and the ants approaching each presented stand at a distance of at most $2 \mathrm{~cm}$ were counted twenty times over ten minutes (Tables 1, 4, fourth column; Figures 3, 4, right parts). Half of the tests were made with the kind of stand set near the food during training placed on the left of the other stand, and half of the tests were performed with that kind of stand placed on the right of the other stand. The twenty counts relative to each stand allowed establishing the ants' proportion of correct responses (i.e. the proportion of ants choosing the kind of stand set near the food during training), these proportions being given in Appendix 1 and 2. After each test, the ants were immediately returned into their foraging area, very near their nest entrance. For each testing session of each experiment, the twenty numbers chronologically obtained for each kind of stand were summed by four, and the five values obtained for each kind of stand were compared to one another using the non-parametric test of Wilcoxon (Siegel \& Castellan, 1989), the result of which is given in Appendix 1 and 2. After having made the four tests on a colony, thus at the end of the two training days, the mean of the four obtained proportions of correct responses was calculated (Tables 1, 4, last column). 


\subsection{Experimental Planning}

The distance effect was examined on colonies A to F. The circle the ants should not memorize had a diameter of $2 \mathrm{~mm}$. The circle the ants should memorize had, for colonies A to $\mathrm{F}$, a diameter of 4, 6, 8, 10, 12, and $14 \mathrm{~mm}$ respectively (Figure 2, lower left part; Figure 3). The size effect was studied on colonies A' to F'. The circle the ants should not memorize had a diameter of 2, 4, 6, 8, 10, $12 \mathrm{~mm}$ respectively, and the circle the ants should memorize had a diameter of 4, 6, 8, 10, 12, $14 \mathrm{~mm}$ respectively (Figure 2, lower right part; Figure 4).

\subsection{Analysis of the Relations Between the Ants' Response and the Distance in Magnitude} Between the Sighted Cues or the Size of the Cues

The variables measuring the distance effect (i.e. the ants' discrimination ability between cues according to the increasing difference in magnitude of these cues) were the difference in size, the mean, and the ratio of the magnitude of the cues. The variables measuring the size effect (i.e. the ants' discrimination ability between cues of equal distance, but of increasing magnitude) were the relative difference between the cues (i.e. their difference in size divided by their mean size, the size of the larger cue, or the size of the smaller cue). The magnitude of the cues was measured by their surface. Using a correlated measure, as the diameter, of course provided similar results. The relation between the observed data and linear, power functions bearing exponents $0.33,0.50$ and 0.75 , as well as logarithmic and second-order fractional polynomial functions (these last with exponents $0.33,0.50$ and 0.75 ) was examined using Statistica v10 software. The exactness of the relation between the ants' scores and variables measuring either the distance in magnitude between the cues or the size of the cues was assessed by the determination index of the curves $\left(R^{2}\right.$, least squares, Levenberg-Marquardt estimation method). No attempt was made to further explore fractional polynomials.

\section{Results}

\subsection{Distance Effect}

During training, the ants were sufficiently numerous at any time around the two cues for seeing and memorizing them (Table 1).

Whatever was the length of the training time (7, 24, 31 or 48 hours) and the diameter of the largest circle (the 'correct' circle to be learned, set near the food), the number of ants sighted near it was always significantly higher than the number of ants sighted near the smaller circle (Wilcoxon test between the two series of counted numbers summed by four over the successive counts: $\mathrm{P}=0.031$; details given in 'Appendix 1'). Thus, the ants duly perceived the difference between the two presented cues. As for the mean conditioning score obtained during the four testing sessions, they increased with the increasing difference in diameter between the two presented cues (Table 1).

As for the analysis of the results, in the course of the six experiments, the ants presented a mean conditioning score increasing from $61.6 \%$ to $80.3 \%$ when trained to a circle with a diameter increasing from $4 \mathrm{~mm}$ to $14 \mathrm{~mm}$ versus a circle with a fixed diameter of $2 \mathrm{~mm}$. The 
ants' response increased thus with the distance (i.e. the difference) between the cues they should memorize and the one they should avoid: this illustrated the 'distance effect' (Table 1). The relation between the ants' response ( $\%$ of conditioning) and the distance in magnitude between the stimuli was examined on the basis of the numerical values given in Table 2 . The variables describing the 'distance' between the two stimuli were the difference, the mean and the ratio between the surface of the circle which should be memorized and the surface of the circle which should be avoided. Whatever how the distance between the two surfaces was characterized, the relation between these surface variables and the ants' response was the best described by a power function with exponent 0.33 . A fractional polynomial function did not provide a much higher fit (Table 3).

Table 1. Ants' responses during the experiments made for studying the distance effect

\begin{tabular}{|c|c|c|c|c|c|c|c|}
\hline \multirow[t]{2}{*}{ Colony } & \multirow[t]{2}{*}{$\begin{array}{l}\varnothing \text { of the } \\
\text { circle set } \\
\text { near the } \\
\text { food }\end{array}$} & \multirow[t]{2}{*}{$\begin{array}{l}\text { Training: } \\
\text { mean } n^{\circ} \text { of } \\
\text { ants near } \\
\text { the circles }\end{array}$} & \multicolumn{4}{|c|}{$\begin{array}{l}\text { Testing: } \mathrm{n}^{\circ} \text { of ants } \\
\text { near the correct circle } v s \text { the wrong one } \\
\text { after...training hours }\end{array}$} & \multirow[t]{2}{*}{$\begin{array}{c}\text { Testing: } \\
\text { mean score }\end{array}$} \\
\hline & & & 7 & 24 & 31 & 48 & \\
\hline A & $4 \mathrm{~mm}$ & 6.3 & $56 v s 35$ & $69 v s 39$ & $54 v s 37$ & $43 v s 27$ & $61.6 \%$ \\
\hline B & $6 \mathrm{~mm}$ & 5.7 & $45 v s 25$ & $41 v s 18$ & $32 v s 17$ & $37 v s 19$ & $66.3 \%$ \\
\hline $\mathrm{C}$ & $8 \mathrm{~mm}$ & 3.7 & $60 v s 31$ & $48 v s 19$ & $47 v s 18$ & $49 v s 23$ & $69.5 \%$ \\
\hline $\mathrm{D}$ & $10 \mathrm{~mm}$ & 9.0 & $46 v s 19$ & $58 v s 17$ & $73 v s 31$ & $68 v s 16$ & $74.8 \%$ \\
\hline $\mathrm{E}$ & $12 \mathrm{~mm}$ & 11.2 & $70 v s 23$ & $61 v s 17$ & $57 v s 20$ & $66 v s 12$ & $78.0 \%$ \\
\hline $\mathrm{F}$ & $14 \mathrm{~mm}$ & 5.7 & $47 v s 12$ & $66 v s 13$ & $46 v s 12$ & $59 v s 16$ & $80.3 \%$ \\
\hline
\end{tabular}

The ants of six different colonies were trained to a black circle of a given diameter set near the food versus a circle of $2 \mathrm{~mm}$ in diameter set far from the food. They were tested in front of these two cues. Their mean score increased with the dimension of the conditional stimulus (the one the ants memorized), thus with the distance in magnitude between the two cues. 


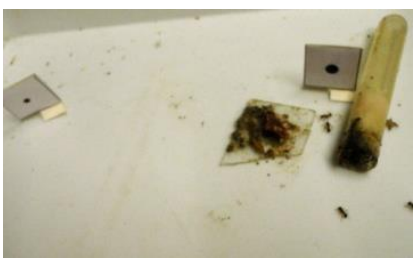

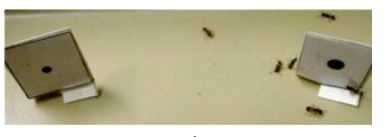

circle $\varnothing 4 \mathrm{~mm} v \mathrm{~s}$ circle $\varnothing 2 \mathrm{~mm}$
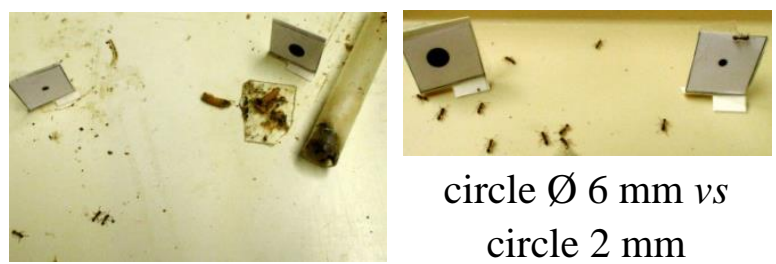

circle $\varnothing 6 \mathrm{~mm} v \mathrm{~s}$ circle $2 \mathrm{~mm}$
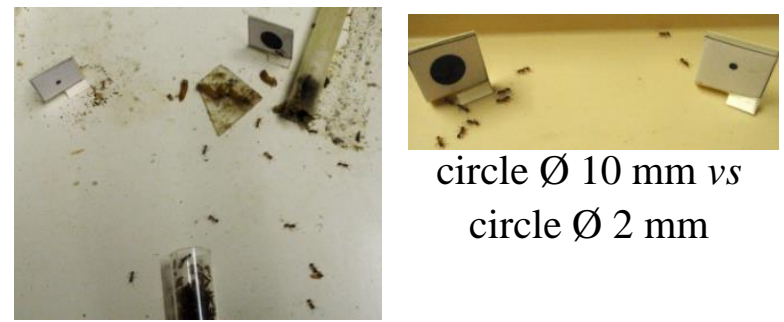

circle $\varnothing 2 \mathrm{~mm}$
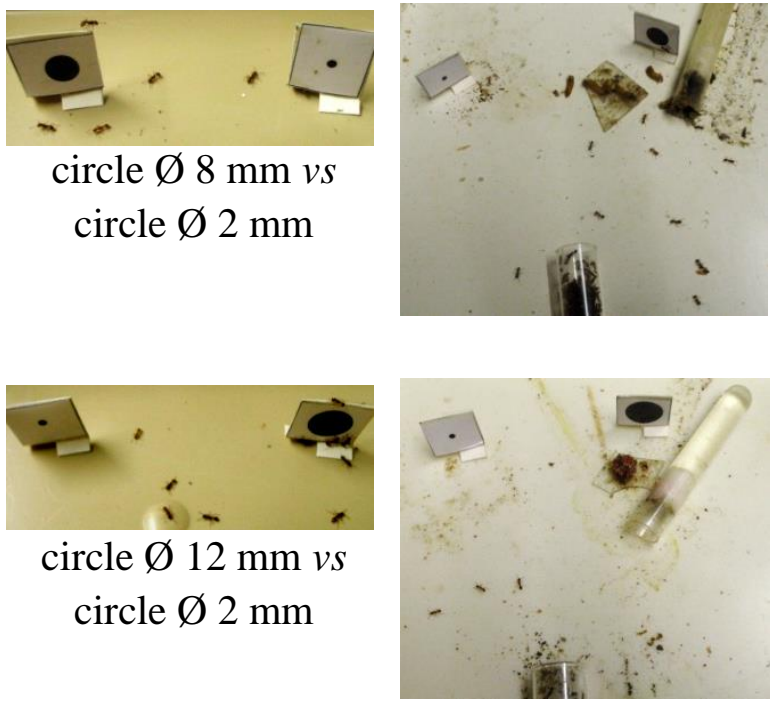

Figure 3. Some views of the experiments made for examining the distance effect on an ant

The ants of six colonies (A to F) were conditioned to a circle set near the food, the diameter of which equaled $4,6,8,10,12$, or $14 \mathrm{~mm} v s$ a circle with a fixed diameter of $2 \mathrm{~mm}$ set far from food. The distance in magnitude between the two stimuli increased from colony A to colony F. The ants responded better to the circle associated with food as its size increased, i.e. as its magnitude became more and more different from that of the circle not associated with food (numerical results in Table 1). More information can be found in the Appendix 1.

Table 2. Surface characteristics of the two visual cues used for examining the distance effect

\begin{tabular}{c|c|c|c|c}
\hline $\begin{array}{c}\text { Diameter } \\
(\varnothing, \mathrm{mm})\end{array}$ & $\begin{array}{c}\text { Surface } \\
\left(\mathrm{S}, \mathrm{mm}^{2}\right)\end{array}$ & $\begin{array}{c}\text { Difference } \\
(\mathrm{S}-3.14, \\
\left.\mathrm{mm}^{2}\right)\end{array}$ & $\begin{array}{c}\text { Mean } \\
(\mathrm{S}+3.14) / 2], \\
\left.\mathrm{mm}^{2}\right)\end{array}$ & $\begin{array}{c}\text { Ratio } \\
(\mathrm{S} / 3.14, \\
\left.\mathrm{mm}^{2}\right)\end{array}$ \\
\hline 2 & 3.14 & - & - & - \\
4 & 12.56 & 9.42 & 7.85 & 4 \\
6 & 28.26 & 25.12 & 15.70 & 9 \\
8 & 50.24 & 47.10 & 26.69 & 16 \\
10 & 78.50 & 75.36 & 40.82 & 25 \\
12 & 113.04 & 109.90 & 58.09 & 36 \\
14 & 153.86 & 150.72 & 79.50 & 49 \\
\hline
\end{tabular}


The ants were trained to a circle the diameter of which equaled 4 to $14 \mathrm{~mm}$ (surface $=\mathrm{S}$ ) versus a circle having a fixed diameter of $2 \mathrm{~mm}$ (surface $=3.14$ ). The relations between their responses (Table 1) and the surface characteristics of the pairs of circles (Table 2) were analyzed (Table 3).

Table 3. Distance effect: fitting of the ants' response to the distance in magnitude between cues as revealed by linear, power, log and second-order fractional polynomial regressions

\begin{tabular}{c|c|c|c|c|c|c}
\hline & linear & $\begin{array}{c}\text { power } \\
0.75\end{array}$ & $\begin{array}{c}\text { power } \\
\text { power }\end{array}$ & log & $\begin{array}{c}\text { polynomial } \\
\text { (vs linear) }\end{array}$ \\
\hline $\begin{array}{c}\text { Difference } \\
(\mathrm{S}-3.14)\end{array}$ & 0.9448 & 0.9741 & 0.9904 & $\mathbf{0 . 9 9 1 3}$ & 0.9652 & $\mathbf{0 . 9 9}(\mathrm{S})$ \\
\hline $\begin{array}{c}\text { Mean } \\
(\mathrm{S}+3.14]) / 2\end{array}$ & 0.9448 & 0.9713 & 0.9881 & $\mathbf{0 . 9 9 2 5}$ & 0.9821 & $\mathbf{0 . 9 9}(\mathrm{S})$ \\
\hline Ratio & & & & & & \\
$(\mathrm{S} / 3.14)$ & 0.9498 & 0.9726 & 0.9893 & $\mathbf{0 . 9 9 2 3}$ & 0.9756 & $\mathbf{0 . 9 9}(\mathrm{S})$ \\
\hline
\end{tabular}

The indicated values are those of the $\mathrm{R}^{2}$ of regressions describing the ants' discrimination score between a circle the diameter of which varied from 4 to $14 \mathrm{~mm}$ (surface $=\mathrm{S}$ ) and a circle with a fixed diameter of $2 \mathrm{~mm}$ (surface $=3.14$ ). The highest values are bold printed; precise values corresponding to polynomial regressions depended on their fractional exponent and are here limited to two decimals. The measures of the distance in magnitude between the two circles are given in Table 2.

\subsection{Size Effect}

During training, the ants were numerous enough at any time all around the two cues for seeing and memorizing them (Table 4).

Whatever the duration of the training time and the size of the two presented cues (i.e. their diameter), the number of ants sighted near the largest cue was always higher than that sighted near the smaller cue (Wilcoxon test on the two obtained series of five sums of counts: $\mathrm{P}=$ 0.031; details are given in Appendix 2). The ants have thus well perceived the difference between the two presented circles. The average conditioning scores corresponding to those obtained during the four testing sessions decreased with the increasing magnitude of the two cues, the difference in diameter of which was kept constant ( $2 \mathrm{~mm}$ ) (Table 4, Figure 4).

As for the analysis of these results, in the course of the six experiments, the ants presented a mean conditioning score decreasing from $77.2 \%$ to $64.4 \%$ after having been trained to a circle the diameter of which increased from $4 \mathrm{~mm}$ to $14 \mathrm{~mm}$ versus a circle the diameter of which correspondingly increased from $2 \mathrm{~mm}$ to $12 \mathrm{~mm}$, the difference in size between the 


\section{Al Macrothink Institute ${ }^{T M}$}

conditional and the non-conditional stimuli always remaining the same $(2 \mathrm{~mm})$. The ants' response decreased thus with the increasing size of the two sighted cues (Table 4). The relation between the ants' response (i.e. the \% of conditioning) and the magnitude of the two visual stimuli appeared to depend on the mean, the ratio or the relative difference between the circle the ants should memorize and the circle they should avoid. The numerical values of these three variables are given in Table 5. The functions which described the best the relation between the ants' accuracy of response and the ratio or a variable characterizing a relative difference of surface between the two cues were a logarithmic or a second-order polynomial function. When the mean of the two surfaces was taken into account, a linear function or a power function with a high fractional exponent (e.g. 0.75) fitted the best, while a fractional polynomial did not significantly improve the fitting (Table 6).
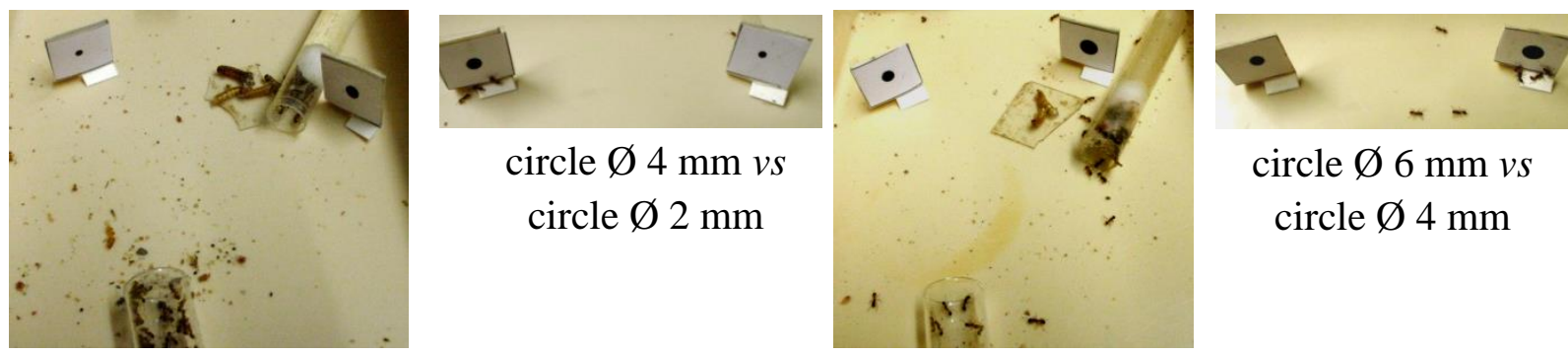

circle $\varnothing 6 \mathrm{~mm} v \mathrm{~s}$

circle $\varnothing 4 \mathrm{~mm}$
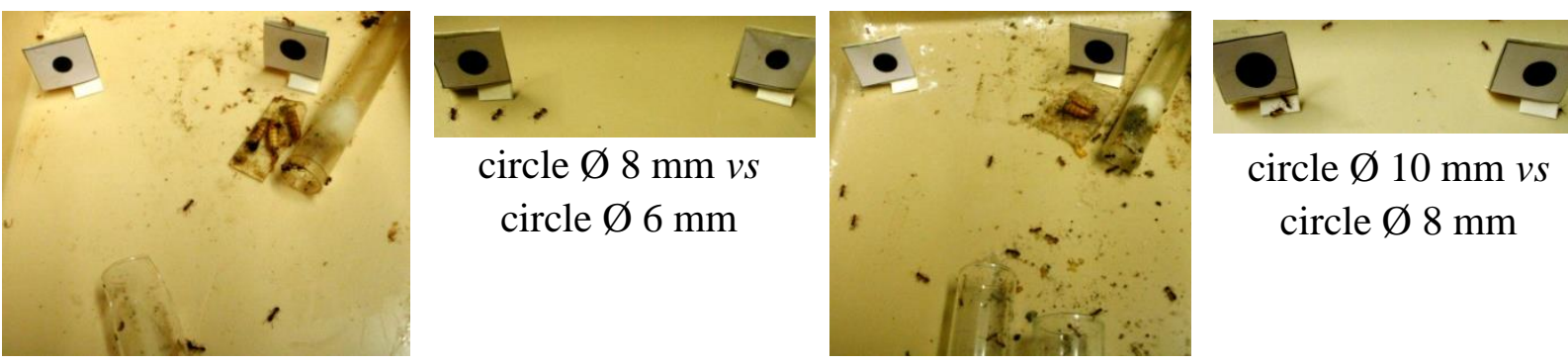

circle $\varnothing 8 \mathrm{~mm} v \mathrm{~s}$ circle $\varnothing 6 \mathrm{~mm}$

circle $\varnothing 10 \mathrm{~mm} v s$ circle $\varnothing 8 \mathrm{~mm}$
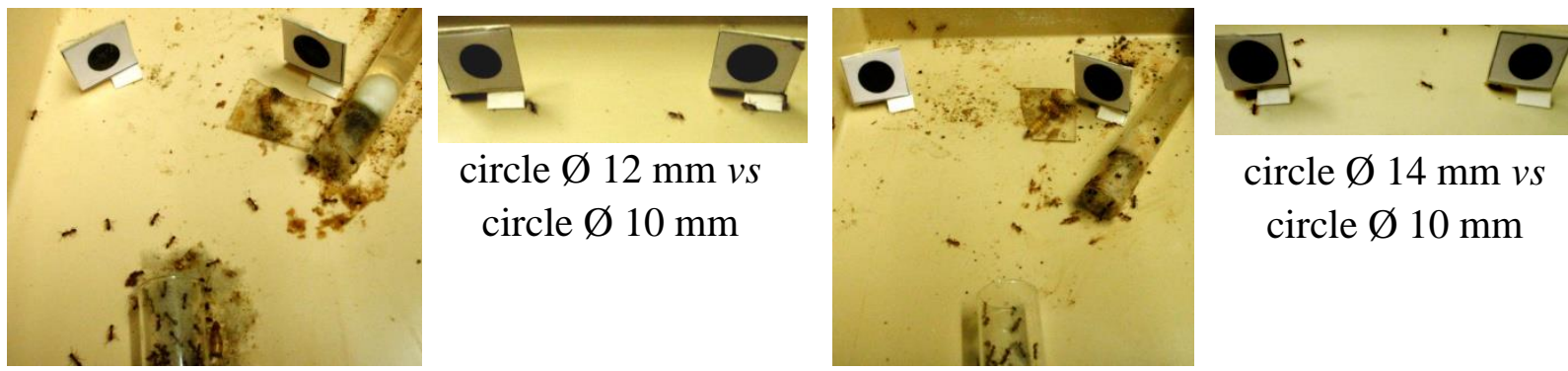

circle $\varnothing 14 \mathrm{~mm} v s$ circle $\varnothing 10 \mathrm{~mm}$

Figure 4. Views of the experiments made for examining the size effect

The ants of six colonies (A' to F') were conditioned to a circle set near the food, the diameter of which varied from 4 to $14 \mathrm{~mm} v s$ a circle set far from food, the diameter of which equaled that of the former circle minus $2 \mathrm{~mm}$, varying thus from 2 to $12 \mathrm{~mm}$. The ants responded less and less accurately as the size of the two presented circles increased, the difference between the circles becoming then less and less perceptible to the ants. Details can be found in the Appendix 2. 
Table 4. Ants' responses during the experiments concerning the size effect

\begin{tabular}{|c|c|c|c|c|c|c|c|}
\hline \multirow[t]{2}{*}{ Colony } & \multirow[t]{2}{*}{$\begin{array}{l}\varnothing \text { of the } \\
\text { circle set } \\
\text { near - far } \\
\text { from food }\end{array}$} & \multirow[t]{2}{*}{$\begin{array}{l}\text { Training: } \\
\text { mean } n^{\circ} \text { of } \\
\text { ants near } \\
\text { the circles }\end{array}$} & \multicolumn{4}{|c|}{$\begin{array}{l}\text { Testing: } \mathrm{n}^{\circ} \text { of ants } \\
\text { near the correct circle } v s \text { the wrong one } \\
\text { after...training hours }\end{array}$} & \multirow[t]{2}{*}{$\begin{array}{l}\text { Testing: } \\
\text { mean score }\end{array}$} \\
\hline & & & 7 & 24 & 31 & 48 & \\
\hline$A^{\prime}$ & $4-2 \mathrm{~mm}$ & 8.4 & $51 v s 16$ & $40 v s 13$ & $56 v s 15$ & $36 v s 10$ & $77.2 \%$ \\
\hline $\mathrm{B}^{\prime}$ & $6-4 \mathrm{~mm}$ & 18.5 & $33 v s 14$ & $50 v s 12$ & $44 v s 17$ & $56 v s 17$ & $74.9 \%$ \\
\hline $\mathrm{C}^{\prime}$ & $8-6 \mathrm{~mm}$ & 11.0 & $38 v s 17$ & $41 v s 16$ & $42 v s 14$ & $51 v s 17$ & $72.8 \%$ \\
\hline D' & $10-8 \mathrm{~mm}$ & 15.0 & $37 v s 16$ & $40 v s 17$ & $38 v s 14$ & $46 v s 24$ & $69.7 \%$ \\
\hline $\mathrm{E}^{\prime}$ & $12-10 \mathrm{~mm}$ & 10.0 & $46 v s 25$ & $49 v s 25$ & $52 v s 20$ & $33 v s 15$ & $68.0 \%$ \\
\hline$F^{\prime}$ & $14-12 \mathrm{~mm}$ & 8.8 & $51 v s 36$ & $38 v s 17$ & $43 v s 23$ & $47 v s 21$ & $65.5 \%$ \\
\hline
\end{tabular}

The ants of six colonies were trained to a black circle of a given diameter set near the food versus a circle with a $2 \mathrm{~mm}$ lesser diameter, set far from the food. They were tested in front of these two cues. Their response score decreased with the dimensions of the conditional and the non-conditional stimuli, thus with the magnitude of the perceived elements.

Table 5. Surface characteristics of the two visual cues used for examining the size effect

\begin{tabular}{c|c|c|c|c|c|c|c}
\hline $\begin{array}{c}\text { Diameter } \\
\mathrm{mm}\end{array}$ & $\begin{array}{c}\text { Surface } \\
\mathrm{mm}^{2}\end{array}$ & $\begin{array}{c}\text { Difference } \\
\mathrm{mm}^{2}\end{array}$ & $\begin{array}{c}\text { Mean } \\
\mathrm{mm}^{2}\end{array}$ & \multicolumn{2}{|c|}{ Ratio } & \multicolumn{3}{|c}{$\begin{array}{r}\text { Relative difference }\left(\mathrm{mm}^{2)}\right. \\
\text { in relation to }\end{array}$} \\
\hline & $(\mathrm{S} 2)$ & $(\mathrm{S} 2-\mathrm{S} 1)$ & $(\mathrm{S} 2-\mathrm{S} 1) / 2$ & $(\mathrm{~S} 2 / \mathrm{S} 1)$ & mean & $\mathrm{S} 2$ & $\mathrm{~S} 1$ \\
\hline 4 & 12.56 & 9.42 & 7.85 & 4.00 & 1.20 & 0.75 & 3.00 \\
6 & 28.26 & 15.70 & 20.41 & 2.25 & 0.77 & 0.56 & 1.25 \\
8 & 50.24 & 21.90 & 39.25 & 1.78 & 0.56 & 0.44 & 0.78 \\
10 & 78.50 & 28.25 & 64.37 & 1.56 & 0.44 & 0.36 & 0.56 \\
12 & 113.04 & 34.54 & 95.77 & 1.44 & 0.36 & 0.31 & 0.44 \\
14 & 153.86 & 40.82 & 133.45 & 1.36 & 0.31 & 0.27 & 0.36 \\
\hline
\end{tabular}

The ants were trained to a circle (of surface S2) the diameter of which varied from 4 to 14 $\mathrm{mm}$ versus a circle (of surface $\mathrm{S} 1$ ) the diameter of which varied from 2 to $12 \mathrm{~mm}$ respectively. The relations between their responses (Table 4) and the surface characteristics of each pair of cues (Table 5) were analyzed (Table 6). 
Table 6. Size effect: fitting of the ants' response to the difference in size between circular cues as revealed by linear, power, log and second-order fractional polynomial regressions

\begin{tabular}{c|c|c|c|c|c|c}
\hline & linear & $\begin{array}{c}\text { power } \\
0.75\end{array}$ & $\begin{array}{c}\text { power } \\
0.50\end{array}$ & $\begin{array}{c}\text { power } \\
0.33\end{array}$ & log & $\begin{array}{c}\text { polynom. } \\
\text { (vs linear) }\end{array}$ \\
\hline $\begin{array}{c}\text { Mean of surfaces } \\
\text { (S2-S1)/2 }\end{array}$ & 0.9878 & $\mathbf{0 . 9 9 2 7}$ & 0.9817 & 0.9639 & 0.8993 & $0.99(\mathrm{NS})$ \\
\hline Ratio of surfaces & $\begin{array}{c}0.6030 \\
\text { S2/S1 }\end{array}$ & $\begin{array}{c}0.6328 \\
(\mathrm{NS})\end{array}$ & 0.6636 & 0.6848 & $\mathbf{0 . 7 2 6 1}$ & $\mathbf{0 . 9 6}(\mathrm{S})$ \\
\hline $\begin{array}{c}\text { Relative difference } \\
\text { (S2-S1)/(S2+S1):2 }\end{array}$ & 0.7697 & 0.8068 & 0.8427 & 0.8657 & $\mathbf{0 . 9 0 6 3}$ & $\mathbf{0 . 9 9}(\mathrm{S})$ \\
\hline $\begin{array}{c}\text { Relative difference } \\
\text { (S2-S1)/S2 }\end{array}$ & 0.8399 & 0.8652 & 0.8890 & 0.9041 & $\mathbf{0 . 9 3 0 6}$ & $\mathbf{0 . 9 9}(\mathrm{S})$ \\
\hline $\begin{array}{c}\text { Relative difference } \\
\text { (S2-S1)/S1 }\end{array}$ & 0.6020 & 0.6593 & 0.7204 & 0.7627 & $\mathbf{0 . 8 4 0 8}$ & $\mathbf{0 . 9 8}(\mathrm{S})$ \\
\hline
\end{tabular}

The indicated values are those of the $\mathrm{R}^{2}$ of regressions describing the ants' discrimination score between two circles (surfaces $=\mathrm{S} 2, \mathrm{~S} 1$ ) of increasing diameter, differing each time by 2 $\mathrm{mm}$. The highest values are bold printed; precise values corresponding to polynomial regressions depended on their fractional exponent and are here limited to two decimals. Characteristics of the difference in size between the circles are given in Table 5.

\subsection{Ants'Response and Weber's Law}

Concerning the distance effect, the ants' response non-linearly increased with the distance between the stimuli, the relation being better fitted by a power (the more with exponent 0.33 ) or a fractional polynomial function than by a logarithmic function. This could be accounted for by Weber's law.

Concerning the size effect, the ants' response varied rather well logarithmically when a variable describing the relative difference between the two circles was taken into account. This could also be accounted for by Weber's law.

We did not use circles presenting a just perceptible difference, but circles obviously different in size. For perfectly verifying Weber's law, we have to conduct novel and adequate experiments based on the search of the 'just noticeable difference' between the stimuli. 


\section{Discussion - Conclusion}

Obviously, M. sabuleti ants more easily perceived the difference between two black circles when the distance in magnitude between these circles was larger (= the distance effect), and less easily distinguished two black circles differing by a width of $2 \mathrm{~mm}$ when these circles were larger (= the size effect).

Concerning the distance effect, it was already known that in vertebrates (see the introduction section), the accuracy of discriminating two similar cues inversely varies with the distance between the dimension of the two cues estimated by the individuals using their own referents. The referents have caused problem in the course of the present work. What kind of referent did the ants use for estimating the difference in magnitude between two circles of same color and brightness: was it their diameter or their area? For analyzing our results, we chose the area of the circles as a potential referent on which the ants could have based their comparison. Furthermore, when having to compare two elements of the same kind but differing by the magnitude of one of their characters, how proceed the ants: do they use the difference between the two elements or their ratio? When experimenting on pigeons, Gibbon and Fairhurst (1994) used the ratio, not the difference. Such a use can effectively explain the distance effect when individuals have to choose between two similar elements differing by their magnitude. Here, we tried the difference, the mean and the ratio between the two circles for tempting to define the relation between such variables and the accuracy of the ants' discrimination between the circles. A power function with exponent 0.33 accounted the best for the ants' discrimination accuracy between circles of increasing magnitude distance.

Concerning the size effect, it has a consequence on the perception of a change in intensity of a stimulus. More explicitly, if a stimulus of small size increases (or decreases), this increase (or decrease) will be easily perceived; if the same change is made on a stimulus of a similar nature but of a larger intensity, this change will be poorly perceived. Having tried the mean, the ratio and relative differences between the circles, we found that the ratio did not express the best the ants' discrimination accuracy between circles. When analyzing the ants' positioning of amounts on their number line, the ratio between amounts was also not the variable expressing the best fit between ants' discrimination accuracy and the successive numbers (Cammaerts \& Cammaerts, 2020). Here, it was the mean of the two sighted surfaces which described the best the size effect affecting the ants' discrimination between circles of increasing magnitude and differing by a constant distance.

The size effect and, at a lower extend, the distance effect are expressions of Weber's law. This law concerns the perception of a difference in intensity between two similar stimuli. The just perceptible difference between two stimuli depends on the size of these stimuli and is a constant proportion of their magnitude. Such a law accounts for a non-linear relation between the individuals' response and the relative difference between two perceived intensities. Here, we did not search for the 'just noticeable difference', but we observed that the data were best approached by a non-linear function when studying the size effect and using the relative difference between the presented circles. Thus, after having showed that a size and a distance effects exist in ants, the future step will be to examine if Weber's law can be applied to these insects. 


\section{References}

Brannon, E. M., \& Merritt, D. J. (2011). Evolutionary foundations of the approximate number system. In S. Dehaene \& E. Brannon (Eds.), 'Space, time and number in the brain: Searching for the foundations of mathematical thought', 207-224. Elsevier Academic Press. https://doi.org/10.1016/B978-0-12-385948-8.00014-1

Brannon, E. M., \& Terrace, H. S. (2000). Representation of the numerosities 1-9 by rhesus macaques (Macaca mulatta). Journal of Experimental Psychology, 26(1), 31-49. psycnet.apa.org > record

Buckley, P. B., \& Gillman, C. B. (1974). Comparisons of digits and dot patterns. Journal of Experimental Psychology, 103(6), 1131-1136. psycnet.apa.org > record

Cammaerts, R., \& Cammaerts, M. C. (2020). Ants' mental positioning of amounts on a number line. International Journal of Biology, 12(1), 30-45. https://doi.org/10.5539/ijb.v12n1p30

Carlyon, R. P., \& Moore, B. C. J. (1984). Intensity discrimination: a severe departure from the Weber's law. The Journal of the Acoustical Society of America, 76, 1369-1376. https://doi.org/10.1121/1.391453

Cattell, J. McK. (1902). The time of perception as a measure of differences in intensity. Philosophische Studien, 19, 63-68. books.google.be > books

Cavonius, C. R., \& Mollon, J. D. (1984). Reaction time as a measure of the discriminability of large colour differences. In C.P. Gibson 'Colour coded vs monochrome electronic displays', Her Majesty's Stationery Office, London, 17.1-17.10. vision.psychol.cam.ac.uk>CavoniusMollon 1984

Cohen, K. R., Tzelgov, J., \& Henik, A. (2008). A synesthetic walk on the mental number line: the size effect. Cognition, 106, 548-557. https://europepmc.org > abstract > med

Curtis, D. W., Paulos, M. A., \& Rule, S. J. (1973). Relation between disjunctive reaction time and stimulus difference. Journal of Experimental Psychology, 99, 167-173. psycnet.apa.org >record

D’Amato, M. R., \& Colombo, M. (1990). The symbolic distance effect in monkeys (Cebus apella). Animal learning \& Behavior, 18(2), 133-140. https://psycnet.apa.org>record >1990-30141-001

Dehaene, S. (1992). Varieties of numerical abilities. Cognition, 44, 1-42. www.ncbi.nlm.nih.gov > pubmed

Dehaene, S. (2003). The neural basis of the Weber-Fechner law: a logarithmic mental number line. Trends in Cognitive Sciences, 7(4), 145-147). http://tics.trends.com

Dehaene, S., Dehaene-Lambertz, G., \& Cohen, L. (1998). Abstract representations of numbers in the animal and human brain. Trends in Neurosciences, 21(8), 355-361. psycnet.apa.org > record > 1998-10243-003 
Ditz, H. M., \& Nieder, A. (2016). Numerosity representations in crows obey the Weber-Fechner law. Proceedings of the Royal Society, B, 283, 20160083. royalsocietypublishing.org > abs > rspb.2016.0083

Emmerton, J., \& Renner, J. C. (2006). Scalar effects in the visual discrimination of numerosity by pigeons. Learning \& Behavior, 34(2), 176-192. link.springer.com $>$ article

Francisco, E., Tannan, V., Zhang, Z., Holden, J., \& Tommerdahl, M. (2008). Vibrotactile amplitude discrimination capacity parallels magnitude changes in somatosensory cortex and follows Weber's law. Experimental Brain research, 49-56. https://doi.org/10.1007/s00221-008-1494-6

Gibbon, J., \& Fairhurst, S. (1994). Ratio versus difference comparators in choice. Journal of the Experimental Analysis of Behavior, 62, 409-434. https://psycnet.apa.org>record

Jordan, K. E., \& Brannon, E. M. (2006). Weber's law influences numerical representations in rhesus macaques (Macaca mulatta). Animal Cognition, 9, 159-172. psycnet.apa.org > record > 2006-08179-001

Kellogg, W. N. (1931). Time of judgment in psychometric measures. American Journal of Psychology, 43, 65-86. psycnet.apa.org > record > 1931-01791-001

Krajcsi, A., \& Kojouharova, P. (2017). Symbolic numerical distance effect does not reflect the difference between numbers. Frontiers in Psychology, 8. https://doi.org/10.3389/fpsyg.2017.02013

Krajcsi, A., Lengyel, G., \& Kojouharova, P. (2016). The source of the symbolic numerical distance and size effects. Frontiers in Psychology, 7(1795). https://doi.org/10.3389/fpsyg.2016.01795

Krajcsi, A., Lengyel, G., \& Kojouharova, P. (2018). Symbolic number comparison is not processed by the Analog Number System : different symbolic and non-symbolic numerical distance and size effects. Frontiers in Psychology, 9(124), 3-16. https://doi.org/10.3389/fpsyg.2018.00124

McGill, W. J., \& Goldberg, J. P. (1968). A study of the near-miss involving Weber's law and pure-tone intensity discrimination. Perception \& Psychophysics, 4(2), 105-109. https://doi.org/10.1121/1.391453

Merten, K., \& Nieder, A. (2008). Compressed scaling of abstract numerosity representations in adult humans and monkeys. Journal of Cognitive Neuroscience, 21(2), 333-346. www.researchgate.net > publication > 5341418_Co

Moyer, R. S., \& Bayer, R. H. (1976). Mental comparison and the symbolic distance effect. $\begin{array}{lll}\text { Cognitive Psychology, } & \text { 8(2), } & \text { 228-246. }\end{array}$ https://doi.org/10.1016/0010-0285(76)90025-6Getrights and content

Moyer, R. S., \& Landauer, T. K. (1967). Time required for judgments of numerical inequality. Nature, 215, 1519-1520. psycnet.apa.org > record 
Rilling, M., \& McDiarmid, C. (1965). Signal detection in fixed-ratio schedules. Science, 148, 526-527. psycnet.apa.org > record > 1965-09712-001

Siegel, S., \& Castellan, N. J. (1989). Nonparametric statistics for the behavioural sciences. McGraw-Hill Book Company, Singapore, 396 pp.

Stevens, S. S. (1961). To honor Fechner and repeal his law. A power function, not a log function, describes the operating characteristic of a sensory system. Science, 133, 80-86. https://doi.org/10.1126/science.133.3446.80

Van Oeffelen, M. P., \& Vos, P. G. (1982). A probabilistic model for the discrimination of visual number. Perception \& Psychophysics, 32(2), 163-170. psycnet.apa.org > record

Washburn, D. A., \& Rumbaugh D. M. (1991). Ordinal judgments of numerical symbols by macaques (Macaca mulatta). Psychological Science, 2(3), 190-193. psycnet.apa.org > record > 1991-29524-001

\section{Appendix 1}

This appendix concerns the study of the distance effect; numerical results are given in Tables 1, 2, 3, and some photos are shown in Figure 3.

\section{1 Conditioning to a Circle $4 \mathrm{~mm}$ in Diameter vs a Circle $2 \mathrm{~mm}$ in Diameter (Colony A)}

During training, the ants were rather numerous at any time all around the two presented cues, being meanly 6.3 on these areas. Tested after 7 training hours, they slightly more reacted to the larger circle, 56 ants being counted in front of that circle while 35 ones were counted in front of the smaller one. They thus responded with a score of $61.5 \%$. Summed by four over the twenty counts, the numbers of ants sighted in front of the larger circle were 14,11, 10, 11 , 10 , and sighted in front of the smaller circle, they were $6,4,8,8,9$. These two series statistically differed (Wilcoxon test: $\mathrm{N}=5, \mathrm{~T}=15, \mathrm{P}=0.031$ ). After 24 training hours, the ants again slightly more reacted to the larger circle than to the smaller one, having been 69 in approaching the former circle and 39 the latter one. They presented thus a conditioning score of $63.9 \%$. Summed by four over the twenty counts, the numbers of ants sighted near the larger circle were $12,13,15,16,13$, and sighted near the smaller circle, 8, 8, 8, 8, 7, these two series statistically differing $(\mathrm{N}=5, \mathrm{~T}=15, \mathrm{P}=0.031)$. After 31 training hours, the ants poorly reacted to the larger circle, though yet somewhat more than to the smaller circle. They were 54 in approaching the larger circle and 37 in approaching the smaller one, presenting thus a conditioning score of $59.3 \%$. Nevertheless, this low score was significant: summed by four, the numbers of ants counted in front of the larger circle were 11, 14, 10, 11, 8 and in front of the smaller circle, they were $9,7,8,7,6,(\mathrm{~N}=5, \mathrm{~T}=15, \mathrm{P}=0.031)$. Finally, after 48 training hours, the ants behaved similarly since 43 ants were counted in front of the larger circle and 27 ones in front of the smaller circle. The ants' conditioning score equaled thus $61.4 \%$. Summed by four over the twenty counts, the numbers of ants sighted near the larger circle were $7,5,7,9,15$, and sighted near the smaller circle, they were $4,3,3,6,11$. These two series statistically differed $(\mathrm{N}=5, \mathrm{~T}=15, \mathrm{P}=0.031)$. The mean score of the ants over 
the 48 training hours equaled $61.6 \%$.

\subsection{Conditioning to a Circle $6 \mathrm{~mm}$ in Diameter vs a Circle $2 \mathrm{~mm}$ in Diameter (Colony B)}

During their training, the ants were sufficiently numerous at any time around the two cues for seeing and memorize them. They were indeed meanly 5.7 on that area during their two training days. After 7 training hours, these ants already reacted more to the larger circle than to the smaller one, 45 ants being counted in front of the larger circle and 25 ones in front of the smaller one. Their conditioning score equaled thus $64.3 \%$. Summed by four over the twenty counts, the numbers of ants sighted near the larger circle were $11,11,8,8,7$, and of those sighted near the smaller circle, $8,5,5,4,3$. These two series of values significantly differed $(\mathrm{N}=5, \mathrm{~T}=15, \mathrm{P}=0.031)$. After 24 training hours, the ants again went preferentially towards the large circle. They were 41 in doing so while 18 ants went to the smaller circle, their conditioning score reaching thus $69.5 \%$. Summed by four over the twenty counts, the numbers of ants sighted near the larger circle were $8,10,10,8,5$, and those sighted near the smaller circle were $1,5,6,4,1$. These two series statistically differed $(\mathrm{N}=5, \mathrm{~T}=15, \mathrm{P}=$ 0.031). After 31 training hours, the ants somewhat less reacted to the larger circle though still more than to the smaller circle, 32 ants being sighted near the larger circle and 17 ones near the smaller circle, what gave a conditioning score of $65.3 \%$. Summed by four over the twenty counts, the numbers of ants approaching the larger circle were $6,5,6,7,8$ and those approaching the smaller circle, $4,2,3,5,3$. These two series of values significantly differed from one another $(\mathrm{N}=5, \mathrm{~T}=15, \mathrm{P}=0.031)$. After 48 training hours, the ants of colony $\mathrm{B}$ went again preferentially to the larger circle, being 37 in doing while 19 ones went to the smaller circle. The ants presented thus at that time a conditioning score of $66.1 \%$. Summed by four, the numbers of ants counted in front of the larger circle were 5, 8, 8, 8, 8, and counted in front of the smaller circle, $1,4,6,4,4$, these two series statistically differing $(\mathrm{N}=$ $5, \mathrm{~T}=15, \mathrm{P}=0.031$ ). The mean conditioning score of the ants over their 48 training hours was $66.3 \%$.

\subsection{Conditioning to a Circle $8 \mathrm{~mm}$ in Diameter vs a Circle $2 \mathrm{~mm}$ in Diameter (Colony C)}

While being trained, a few ants were present at any time near these two cues, being meanly 3.7 on these areas. After 7 training hours, these ants already went mostly to the larger circle: 60 ants have been counted there while 31 have been counted near the smaller circle. The ants' conditioning score equaled thus $65.9 \%$ at that time. Summed by four, the numbers of ants approaching the larger circle were $12,14,15,11,8$, and of ants approaching the smaller circle, $8,5,7,7,4$. These two series of five values significantly differed $(\mathrm{N}=5, \mathrm{~T}=15, \mathrm{P}=0.031)$. After 24 training hours, the ants went more frankly to the larger circle. They were 48 in doing so, while 19 ones went to the smaller circle. The ants' conditioning score equaled then $71.6 \%$. Summed by four over the twenty counts, the numbers of ants sighted in front of the larger circle were $9,10,8,8,12$, and sighted near the smaller circle, $3,3,3,6,4$. These two series of five values statistically differed $(\mathrm{N}=5, \mathrm{~T}=15, \mathrm{P}=0.031)$. After 31 training hours, the ants behaved similarly, being 47 in approaching the larger circle and 18 in approaching the smaller circle. The ants presented thus at that time a conditioning score of $72.3 \%$. Summed by four, the numbers of ants sighted in front of the larger circle were $14,8,8,9,8$, and sighted in front 
of the smaller circle, $6,4,3,2,3$. These two series once more significantly differed $(\mathrm{N}=5, \mathrm{~T}$ $=15, \mathrm{P}=0.031)$. After 48 training hours, the ants went on moving essentially towards the larger circle though somewhat less than during the two previous testing sessions. They were indeed 49 in doing so while 23 ants went to the smaller circle, their conditioning score equaling thus $68.1 \%$. Summed by four over the twenty counts, the numbers of ants sighted near the larger circle were $7,9,9,11,13$, and those of ants sighted near the smaller circle were $2,5,4,6,6$. These two series of values significantly differed $(\mathrm{N}=5, \mathrm{~T}=15, \mathrm{P}=0.031)$. The mean of the ants' conditioning score over their 48 training hours equaled $69.5 \%$.

\subsection{Conditioning to a Circle $10 \mathrm{~mm}$ in Diameter vs a Circle $2 \mathrm{~mm}$ in Diameter (Colony D)}

During their training, the ants were numerous at any time all around the two presented cues, being meanly 9.0 on these areas. Tested after 7 training hours, these ants went obviously mostly to the larger circle, 46 ants being counted near that circle while 19 ones were counted near the smaller circle, the ants presenting thus a conditioning score of $70.8 \%$. Summed by four over the twenty counts, the numbers of ants approaching the larger circle were 10, 7, 8, 14,10 , and of ants approaching the smaller circle, 4, 1, 3, 4, 7. These two series statistically differed $(\mathrm{N}=5, \mathrm{~T}=15, \mathrm{P}=0.031)$. After 24 training hours, the same ants were very numerous in reacting essentially to the larger circle. They were 58 in doing so while 17 ants went to the smaller circle. The ants presented thus at that time a conditioning score of $77.3 \%$. Summed by four, the numbers of ants approaching the larger circle were 9, 12, 14, 11, 12, and approaching the smaller circle, $0,2,7,4,4$. These two series of values of course statistically differed $(\mathrm{N}=5, \mathrm{~T}=15, \mathrm{P}=0.031)$. After 31 training hours, the ants reacted again mostly to the larger circle though slightly less than after 24 hours. In fact, 73 ants were counted in front of the larger circle while 31 ones were counted in front of the smaller circle, the ants presenting thus a conditioning score of $70.2 \%$. Summed by four over the twenty counts, the numbers of ants sighted near the larger circle equaled 10,10,13,17, 23, and those sighted near the smaller circle were $5,3,6,7,10$. These two series of values significantly differed $(\mathrm{N}$ $=5, \mathrm{~T}=15, \mathrm{P}=0.031$ ). After 48 training hours, the ants very obviously went mostly to the larger circle, being 68 in doing so while 16 ants went to the smaller circle. The ants' conditioning score reached then $81.0 \%$. Summed by four over the twenty counts, the numbers of ants sighted in front of the larger circle were 13,17,11,12, 15, and sighted in front of the smaller circle, $4,2,2,4,4$. The two obtained series of values statistically differed $(\mathrm{N}=5, \mathrm{~T}=$ $15, \mathrm{P}=0.031$ ). Over their 48 training hours, the ants presented a mean conditioning score of $74.8 \%$.

\subsection{Conditioning to a Circle $12 \mathrm{~mm}$ in Diameter vs a Circle $2 \mathrm{~mm}$ in Diameter (Colony E)}

During their training, a lot of ants were present at any time all around these two cues, being meanly 11.2 in doing so. Tested after 7 training hours, these ants approached essentially the larger circle: 70 ants were counted near that circle and 23 ones were counted near the smaller circle. Thus, the ants presented already a conditioning score of $75.3 \%$. Summed by four over the twenty counts, the numbers of ants sighted in front of the larger circle were 15, 13, 13, 15, 14 , and sighted in front of the smaller circle, 5, 4, 4, 4, 6. These two series of five values significantly differed $(\mathrm{N}=5, \mathrm{~T}=15, \mathrm{P}=0.031)$. After 24 training hours, the same ants again 
went essentially towards the larger circle, being 61 in doing so while 17 ants went to the smaller circle. The ants' conditioning score equaled thus at that time $78.2 \%$. Summed by four, the numbers of ants counted near the larger circle were $11,13,11,11,15$, and counted near the smaller circle, $2,3,3,3,6$. These two series statistically differed $(\mathrm{N}=5, \mathrm{~T}=15, \mathrm{P}=$ 0.031). After 31 training hours, the ants once more went essentially to the larger circle, though a little less than after 24 training hours. They were 57 in doing so while 20 ants went to the smaller circle, the ants' conditioning score equaling thus $74.0 \%$. Summed by four, the numbers of ants approaching the larger circle were 10,11,13,12,11, and approaching the smaller circle, $3,4,2,6,5$. The two obtained series of values significantly differed $(\mathrm{N}=5, \mathrm{~T}$ $=15, \mathrm{P}=0.031)$. After 48 training hours, the ants went very obviously mostly to the larger circle, being 66 in doing so, while 12 ants went to the smaller circle. The ants presented then a conditioning score of $84.6 \%$. Summed by four over the twenty counts, the numbers of ants sighted near the larger circle were 14,11, 10, 13, 18 and seen near the smaller circle, 3, 1, 2, 2, 4. These two series of values statistically differed $(\mathrm{N}=5, \mathrm{~T}=15, \mathrm{P}=0.031)$. The mean conditioning score the ants presented over their 48 training hours amounted $78.0 \%$.

\subsection{Conditioning to a Circle $14 \mathrm{~mm}$ in Diameter vs a Circle $2 \mathrm{~mm}$ in Diameter (Colony F)}

During their training, the ants were rather numerous all around the two presented cues, being meanly 5.7 at any time on this area. When tested after 7 training hours, these ants went essentially towards the larger circle. They were 47 in doing so while 12 ants went to the smaller circle. The ants' conditioning score equaled then $79.7 \%$. Summed by four over the twenty counts, the numbers of ants counted in front of the larger circle were $8,13,10,8,8$, and counted in front of the smaller circle, 2, 4, 3, 1, 2. These two series of values significantly differed $(\mathrm{N}=5, \mathrm{~T}=15, \mathrm{P}=0.031)$. After 24 training hours, the same ants were more inclined to go towards the larger circle, being 66 in doing so while 13 ants went to the smaller circle. The ants presented then a conditioning score of $83.5 \%$. Summed by four, the numbers of ants approaching the larger circle were 9, 13, 17, 16, 11, and approaching the smaller circle, 1, 2, $2,4,4$. The two obtained series of values significantly differed $(\mathrm{N}=5, \mathrm{~T}=15, \mathrm{P}=0.031)$. After having been trained for 31 hours, the ants went again mostly to the larger circle though somewhat less than previously. They were 46 in going to that circle and 12 in going to the smaller circle, their conditioning score equaling thus $79.3 \%$. Summed by four over the twenty counts, the numbers of ants sighted near the larger circle were 12, 11, 7, 9, 7, and those sighted near the smaller circle, 3, 2, 1, 4, 2. These two series of values statistically differed (N $=5, \mathrm{~T}=15, \mathrm{P}=0.031$ ). Finally, after 48 training hours, the same ants once more went preferentially to the larger circle, being 59 in doing so while 16 ants went to the smaller circle. The ants presented at that time a conditioning score of $78.7 \%$. Summed by four over the twenty counts, the numbers of ants counted in front of the larger circle were 12, 10, 10, 13, 14 , and counted in front of the smaller circle, $3,3,4,4,2$. The two obtained series of values significantly differed. The mean conditioning score reached by the ants over their 48 training hours reached $80.3 \%$. 


\section{Appendix 2}

This appendix concerns the study of the size effect; numerical results are given in Tables 4, 5, 6 and some photos are shown in Figure 4.

\subsection{Conditioning to a Circle $4 \mathrm{~mm}$ in Diameter vs a Circle $2 \mathrm{~mm}$ in Diameter (Colony A')}

During their training, the ants were numerous enough all around the two presented cues for seeing them during long time periods, being meanly 8.4 at any time on this area. Tested after 7 hours, the ants already went essentially to the larger circle, being 51 in having done so while 16 ants went to the smaller circle. The ants presented thus a conditioning score of $76.1 \%$. Summed by four over the twenty counts, the numbers of ants sighted near the larger circle equaled 13, 12, 9, 7, 10, and those sighted near the smaller circle were 2, 4, 3, 3, 4, these two series statistically differing $(\mathrm{N}=5, \mathrm{~T}=15, \mathrm{P}=0.031)$. After 24 training hours, the same event occurred: the ants went mostly to the larger circle, being 40 in doing so while 13 went to the smaller circle. They presented thus a conditioning score of $75.5 \%$. Summed by four, the numbers of ants counted near the larger circle were $7,8,8,6,11$, and counted near the smaller circle, $2,2,4,3,3$. The two series statistically differed $(\mathrm{N}=5, \mathrm{~T}=15, \mathrm{P}=0.031)$. After 31 training hours, once more they approached essentially the larger circle: they were 56 in doing so while 15 ants approached the smaller circle. The ants' conditioning score equaled thus then $78.9 \%$. Summed by four, the numbers of ants sighted in front of the larger circle were $11,13,11,12,9$, and sighted in front of the smaller circle, 3, 2, 3, 4, 3. These two series of values significantly differed $(\mathrm{N}=5, \mathrm{~T}=15, \mathrm{P}=0.031)$. After 48 training hours, the ants similarly responded, going essentially towards the larger circle. In total, 36 ants were counted near the larger circle and 10 ones near the smaller one, the ants presenting thus a conditioning score of $78.3 \%$. Summed by four, the numbers of ants sighted in front of the larger circle were $4,10,9,8,5$, and sighted in front of the smaller circle, $0,3,3,3,1$. These two series significantly differed $(\mathrm{N}=5, \mathrm{~T}=15, \mathrm{P}=0.031)$. The ants' mean conditioning score presented over the 48 training hours equaled $77.2 \%$.

\subsection{Conditioning to a Circle $6 \mathrm{~mm}$ in Diameter vs a circle $4 \mathrm{~mm}$ in Diameter (Colony B')}

During their training, the ants were very numerous in moving or stating in the vicinity of the two presented cues, being meanly 18.5 at any time of this area. After 7 training hours, they mostly went to the larger circle, being 33 in doing so while 14 ants went to the smaller circle. They have thus reached at that time a conditioning score of $70.2 \%$. Summed by four over the twenty counts, the numbers of ants approaching the larger circle were 5, 5, 7, 7, 9, and approaching the smaller circle, $2,2,2,3,5$. The two series of values statistically differed $(\mathrm{N}=$ $5, \mathrm{~T}=15, \mathrm{P}=0.031$ ). After having been trained for 24 hours, the same ants went more promptly to the larger circle. They were indeed 50 in doing so while 12 went to the smaller circle. They thus presented a conditioning score of $80.7 \%$. Summed by four over the twenty counts, the numbers of ants sighted near the larger circle were $12,11,11,8,8$, and sighted near the smaller circle, 2, 1, 3, 2, 4. The two obtained series of five values statistically differed $(\mathrm{N}=5, \mathrm{~T}=15, \mathrm{P}=0.031)$. After 31 training hours, the ants went again mostly to the larger circle though somewhat less than during the previous testing session. In fact, 44 ants were counted near the larger circle and 17 ones near the smaller circle, the ants presenting 
thus a conditioning score of $72.1 \%$. Summed by four, the numbers of ants reacting to the larger circle were $6,10,10,10,8$, and reacting to the smaller circle, $1,4,4,5,3$. These two series significantly differed $(\mathrm{N}=5, \mathrm{~T}=15, \mathrm{P}=0.031)$. Finally, after 48 training hours, the same ants went on approaching essentially the larger circle, being 56 in doing so while 17 ants approached the smaller circle. The ants presented then a conditioning score of $76.7 \%$. Summed by four, the numbers of ants counted near the larger circle were 12, 8, 12, 16, 8, and counted near the smaller circle, $3,3,6,5,0$. These two series of values significantly differed $(\mathrm{N}=5, \mathrm{~T}=15, \mathrm{P}=0.031)$. The mean conditioning score presented by the ants over their 48 training hours was $74.9 \%$.

\subsection{Conditioning to a Circle $8 \mathrm{~mm}$ in Diameter vs a circle $6 \mathrm{~mm}$ in Diameter (Colony C')}

During their training, the ants of colony C' were numerous enough all around the two presented cues for seeing and memorizing them. They were indeed meanly 11.0 in being present on this area at any time. Tested after 7 training hours, these ants went mostly to the larger circle. In fact, 38 ants were counted in front of that circle and 17 ones in front of the smaller circle, the ants having then a conditioning score of $69.1 \%$. Summed by four over the twenty counts, the numbers of ants reacting to the larger circle were $8,8,7,7,8$, and reacting to the smaller one, $4,5,2,3,3$. These two series significantly differed $(\mathrm{N}=5, \mathrm{~T}=15, \mathrm{P}=$ 0.031). Tested after 24 training hours, the same ants went somewhat more obviously essentially to the larger circle, 41 ants having been counted in front of that circle while 16 ones have been counted in front of the smaller circle. The ants' conditioning score equaled at that time $71.9 \%$. Summed by four, the numbers of ants reacting to the larger circle were 6,9 , $12,7,7$, and reacting to the smaller circle, 2, 3, 5, 3, 3. The two obtained series of values statistically differed $(\mathrm{N}=5, \mathrm{~T}=15, \mathrm{P}=0.031)$. After 31 training hours, the ants were still more numerous in going mostly to the larger circle: they were 42 in doing so while 14 ones went to the smaller circle, what showed a conditioning score of $75.0 \%$. Summed by four, the numbers of ants sighted near the larger circle were $11,7,8,8,8$, and those sighted near the smaller circle, $3,2,4,3,2$. These two series of values significantly differed $(\mathrm{N}=5, \mathrm{~T}=15, \mathrm{P}$ $=0.031$ ). After a total of 48 training hours, the ants went once more mostly to the larger circle, being 51 in doing so, while 17 ants went to the smaller circle. This last assessed ants' conditioning score equaled thus $75.0 \%$. Summed by four over the twenty counts, the numbers of ants sighted in front of the larger circle were 11,13,8,9,10, and sighted in front of the smaller circle, $4,4,2,2,5$. The two obtained series of values statistically differed $(\mathrm{N}=5, \mathrm{~T}=$ $15, \mathrm{P}=0.031$ ). The ants' mean conditioning score was $72.8 \%$.

\subsection{Conditioning to a Circle $10 \mathrm{~mm}$ in Diameter vs a Circle $8 \mathrm{~mm}$ in Diameter (Colony D')}

During their training, the ants of colony D' were very numerous all around the two presented cues. They were indeed meanly 15 at any time there. After 7 training hours, these ants went mostly towards the larger circle since 37 ones were counted in front of that circle while 16 ones were counted in front of the smaller circle. The ants presented then a conditioning score of $69.8 \%$. Summed by four over the twenty counts, the numbers of ants approaching the larger circle were $6,9,8,7,7$, and approaching the smaller circle, 1, 4, 3, 4, 4. These two series of values significantly differed $(\mathrm{N}=5, \mathrm{~T}=15, \mathrm{P}=0.031)$. After having been trained for 
24 hours, the ants went again essentially to the larger circle, 40 ants having been counted in front of that circle and 17 ones in front of the other circle, the ants' conditioning score equaling $70.2 \%$. Summed by four, the numbers of ants reacting to the larger circle were 9,10 , $0,8,4$, and those reacting to the smaller circle, $3,4,2,4,4$. These two series of values differed at the limit of significance $(\mathrm{N}=4, \mathrm{~T}=10, \mathrm{P}=0.063)$. After 31 training hours, the same ants' preference occurred: 38 ants were counted near the larger circle and 14 ones near the smaller circle, the ants' conditioning equaling thus $73.1 \%$. Summed by four over the twenty counts, the numbers of ants sighted in front of the larger circle were 5, 8, 8,6,11, and those sighted in front of the smaller circle, 1, 3, 4, 2, 4. These two series statistically differed $(\mathrm{N}=5, \mathrm{~T}=15, \mathrm{P}=0.031)$. After a total of 48 training hours, the ants went again mostly to the larger circle but did so somewhat less than in previous tests. In fact, 46 ants were sighted near the larger circle and 24 ones near the smaller circle, the ants presenting thus a conditioning score of $65.7 \%$. Summed by four, the numbers of ants counted near the larger circle were 10 , $8,9,11,8$, and counted near the smaller circle, 6, 5, 6, 7, 0. These two series of values statistically differed $(\mathrm{N}=5, \mathrm{~T}=15, \mathrm{P}=0.031)$. The mean conditioning score presented by the ants over their 48 training hours was $69.7 \%$.

\subsection{Conditioning to a Circle $12 \mathrm{~mm}$ in Diameter vs a Circle $10 \mathrm{~mm}$ in Diameter (Colony E')}

During their training, the ants of colony E' were numerous at any time all around the presented cues: they were meanly 10 on that area. After 7 training hours, they went more to the larger than to the smaller circle: 46 ants were counted near the former circle and 25 ones near the latter circle, the ants conditioning score equaling thus $64.8 \%$. Summed by four over the twenty counts, the numbers of ants approaching the larger circle were 7, 12, 13, 7, 7, and approaching the smaller circle, $4,6,6,5,4$. These two series statistically differed $(\mathrm{N}=5, \mathrm{~T}=$ $15, \mathrm{P}=0.031$ ). After 24 training hours, the ants went again mostly towards the larger circle: 49 ants were counted in front of that circle and 25 in front of the smaller circle. The ants' conditioning score equaled then $66.2 \%$. Summed by four, the numbers of ants reacting to the larger circle were $12,15,8,6,8$, and reacting to the smaller circle, 9, 8, 3, 2, 3. These two series statistically differed $(\mathrm{N}=5, \mathrm{~T}=15, \mathrm{P}=0.031)$. After 31 training hours, the ants went somewhat more promptly to the larger circle, being 52 in doing so while 20 went to the smaller circle. The ants' conditioning score reached thus at that time $72.2 \%$. Summed by four, the numbers of ants sighted near the larger circle were 11,10,14,10, 7, and those sighted near the smaller circle, $2,4,6,5,3$. These two series significantly differed $(\mathrm{N}=5, \mathrm{~T}=15, \mathrm{P}=$ 0.031). After a total of 48 training ants, the ants went again mostly to the larger circle, though less than previously. In fact, 33 ants were counted near the larger circle and 15 ones near the smaller circle, the ants' conditioning score equaling thus $68.0 \%$. Summed by four, the numbers of ants sighted in front of the larger circle were $6,8,8,6,5$, and sighted in front of the smaller circle, $2,3,4,3,3$. These two series statistically differed $(\mathrm{N}=5, \mathrm{~T}=15, \mathrm{P}=$ 0.031). The mean conditioning score presented by the ants over their 48 training hours equaled $68.0 \%$.

\subsection{Conditioning to a Circle $14 \mathrm{~mm}$ in Diameter vs a Circle $12 \mathrm{~mm}$ in Diameter (Colony F')}

During their training, the ants were meanly 8.8 in moving or staying in the vicinity of the two 
presented cues. After 7 training hours, these ants went a little more to the larger circle than to the smaller one: 51 ants were counted near the former circle and 36 ones near the latter circle, the ants' conditioning equaling thus only $58.6 \%$. Summed by four over the twenty counts, the numbers of ants reacting to the larger circle were $8,11,12,12,8$, and reacting to the smaller circle, $4,8,9,11,4$. These two series of five values statistically differed $(\mathrm{N}=5, \mathrm{~T}=15, \mathrm{P}=$ 0.031). After having been trained for 24 hours, the ants went obviously more to the larger circle, being 38 in doing so while 17 ants went to the smaller circle. The ants' conditioning score was thus $69.1 \%$. Summed by four, the numbers of ants counted in front of the larger circle were $10,7,8,8,5$, and counted in front of the smaller circle, 3, 3, 4, 4, 3. These two series of five values statistically differed $(\mathrm{N}=5, \mathrm{~T}=15, \mathrm{P}=0.031)$. When tested after 31 training hours, the ants went again essentially to the larger circle but less than during the previous test. They were 43 in doing so while 23 ants went to the smaller circle, their conditioning score equaling thus $65.2 \%$. Summed by four, the numbers of ants sighted near the larger circle were $6,10,5,10,12$, and those sighted near the smaller circle, 2, 6, 3, 6, 6 . These two series statistically differed $(\mathrm{N}=5, \mathrm{~T}=15, \mathrm{P}=0.031)$. After a total of 48 training hours, the ants went again, and this time rather well, mostly to the larger circle: 47 ants did so while 21 ants went to the smaller circle. The last ants' conditioning score equaled thus $69.1 \%$. Summed by four the numbers of ants counted near the larger circle were 8, 12, 11, 7, 9, and counted near the smaller circle, 3, 5, 5, 4, 4. These two series of five values significantly differed $(\mathrm{N}=5, \mathrm{~T}=15, \mathrm{P}=0.031)$. The mean conditioning score presented by the ants over their 48 training hours, equaled $65.5 \%$.

\section{Copyright Disclaimer}

Copyright for this article is retained by the author(s), with first publication rights granted to the journal.

This is an open-access article distributed under the terms and conditions of the Creative Commons Attribution license (http://creativecommons.org/licenses/by/4.0/). 